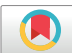

Check tor
updates

Letter to the Editor

\title{
Gastroesophageal Reflux Disease Could Progress to Achalasia
}

TO THE EDITOR: We read with interest the article entitled "Is Gastroesophageal Reflux Disease and Achalasia Coincident or Not" published in January 2017, by Jung and Park. ${ }^{1}$ The title raises a very interesting question, however, in the end, the question remains unanswered and the paper mostly focuses on the overlapping symptoms between gastroesophageal reflux disease (GERD) and achalasia, thus leading to diagnostic delay in many achlasia patients. The arguments for and against whether the coexistence of the 2 diseases is accidental or not, are poorly supported. We have previously put the question to ourselves as well, and based on our own experience and thorough review of the literature, we believe that the development of achalasia in certain GERD patients is not a coincidence, but that there may be a cause-and-effect relationship between the 2 diseases. ${ }^{2}$ Our surgical work team have operated on over 40 patients with achalasia in the past 15 years and in 10\% of them, the etiological role of reflux arose. ${ }^{3}$ Similar to the fact that the human body has developed several aero-digestive reflexes to protect the airways from aspiration, ${ }^{4}$ we suggest that chronic acid exposure may lead to structural and functional changes in the esophagus, as, for example, to the development of achalasia. By this means, the narrowing of the distal lumen of the esophagus could be interpreted as another kind of protective mechanism of the body aiming at preventing the refluxate entering the esophagus or beyond. A convincing argument for the chronological order, and presumably, the casual relationship between reflux and achalasia is that several reports have been published describing the presence of Barrett's esophagus among untreated achalasia patients. ${ }^{5,6}$ The most plausible explanation for this is that these patients had long-standing reflux disease before the development of achalasia. Also, several cases have been described where achalasia occured with concomitant hiatal hernia ${ }^{7}$ and it is well-known that hiatal hernia induces the development of GERD. Among our own untreated achalasia cases we also had one patient with concomitant Barrett's esophagus and one with hiatal hernia. Altorjay et $\mathrm{al}^{8,9}$ reported an interesting observation after comparing muscle samples taken from the lower esophageal sphincter of reflux patients and those of a control group. They found that reflux patients had smooth muscle hypertrophy and enteric ganglionitis at the gastroesophageal junction, and they suggested that these morphological changes might result in various functional esophageal diseases. Based on these findings we assume that in certain cases GERD may progress to achalasia.

\section{Laura Bognar, Andras Vereczkei, and Ors Peter Horvath} Department of Surgery, University of Pécs, Hungary

1. Jung DH, Park H. Is gastroesophageal reflux disease and achalasia coincident or not? J Neurogastroenterol Motil 2017;23:5-8.

2. Király A, Illés A, Undi S, Varga G, Kalmár K, Horváth PO. Gastroesophageal reflux disease progressing to achalasia. Dis Esophagus 2005;18:355-358.

3. Bognar L, Horvath OP, Jancso G, Vereczkei A. GERD: a debated background of achalasia. J Gastrointest Dig Syst 2016;6:432.

4. Dua K, Surapaneni SN, Kuribayashi S, Hafeezullah M, Shaker R. Protective role of aerodigestive reflexes against aspiration: study on subjects with impaired and preserved reflexes. Gastroenterology 2011;140:19271933.

5. Guo JP, Gilman PB, Thomas RM, Fisher RS, Parkman HP. Barrett's esophagus and achalasia. J Clin Gastroenterol 2002;34:439-443.

6. Cantù P, Savojardo D, Baldoli D, Bonavina L, Penagini R. Barrett's esophagus in untreated achalasia: 'guess who's coming to dinner' first. Dis Esophagus 2008;21:473.

7. Kotidis KN, Rogers ML, Knowles KR, Beggs FD. Coexisting achalasia and paraoesophageal hiatal hernia. Eur J Cardiothorac Surg 2002;21:130-132.

8. Altorjay A, Szilagyi A, Arato G, et al. Morphological changes in the lower esophageal sphincter influencing the result of antireflux surgical interventions in chronic gastroesophageal reflux disease. Hepatogastroenterology 2006;53:342-347.

9. Altorjay A, Juhasz A, Kellner V, Sohar G, Fekete M. Metabolic changes in the lower esophageal sphincter influencing the result of anti-reflux surgical interventions in chronic gastroesophageal reflux disease. World J Gastroenterol 2005;11:1623-1628.

\section{Conflicts of interest: None}

